\title{
Magnesium and the Cardiometabolic Syndrome
}

\author{
Mario Barbagallo • Ligia J. Dominguez
}

Published online: 14 March 2012

(C) Springer Science+Business Media, LLC 2012

\begin{abstract}
The cardiometabolic syndrome is a cluster of metabolic factors that increase an individual's risk of developing cardiovascular disease and type 2 diabetes mellitus. The metabolic risk factors that cluster in the syndrome include insulin resistance, hypertension, impaired glucose tolerance, central obesity, and dyslipidemia. Other abnormalities, such as chronic proinflammatory and prothrombotic states and oxidative stress, have been added to the syndrome. Magnesium $(\mathrm{Mg})$ plays a key role in regulating insulin action, glucose uptake, and vascular tone. Many experimental, clinical, and epidemiologic studies have shown a clear link between Mg status and any component included in the constellation. Increasing evidence suggests a role for $\mathrm{Mg}$ deficiency as a possible unifying mechanism underlying the coincidence among those apparently disparate clinical conditions clustering in the syndrome. Although the use of Mg supplements has been suggested as a potential tool in the prevention of the cardiometabolic syndrome, this needs to be demonstrated by future prospective studies.
\end{abstract}

Keywords Magnesium · Calcium · Cardiometabolic syndrome $\cdot$ Metabolic diseases $\cdot$ Cardiovascular disease . Type 2 diabetes mellitus · Insulin resistance · Glucose intolerance - Blood pressure - Hypertension - Dyslipidemia . Visceral adiposity $\cdot$ Coagulation factors · Inflammation . Oxidative stress $\cdot$ Aging

\footnotetext{
M. Barbagallo $(\bowtie) \cdot$ L. J. Dominguez

Geriatric Unit, Department of Internal Medicine and Medical Specialties (DIMIS), University of Palermo, Via del Vespro 129, 90127 Palermo, Italy e-mail: mario.barbagallo@unipa.it

L. J. Dominguez

e-mail: ligia.dominguez@unipa.it
}

\section{Introduction}

Magnesium $(\mathrm{Mg})$ is the second most abundant intracellular cation after potassium present in living cells. Most of the $\mathrm{Mg}$ present in the adult human body is distributed in the intracellular compartment (99\%), with only $1 \%$ in the extracellular fluid [1]. The small intestine is the main site of $\mathrm{Mg}$ absorption, whereas Mg excretion is mainly performed through renal pathways. Serum Mg exists in three forms: a protein-bound fraction (25\% bound to albumin and $8 \%$ bound to globulins), a chelated fraction (12\%), and the metabolically active ionized fraction $\left(\mathrm{Mg}^{-}\right.$ion, $\left.55 \%\right)$ [2]. Even if there is no known hormonal factor specifically involved in the regulation of $\mathrm{Mg}$ metabolism, several hormones are recognized to have an effect on $\mathrm{Mg}$ balance and transport, such as parathyroid hormone, calcitonin, and catecholamines. A major role for insulin has been proposed, and accumulating data have confirmed that insulin is a key hormone in the regulation of $\mathrm{Mg}$ metabolism [1, 3]. Insulin has specific ionic effects to stimulate the transport of $\mathrm{Mg}$ from the extracellular to the intracellular compartment, thus increasing Mg intracellular content [4].

\section{Cardiometabolic Syndrome}

The cardiometabolic syndrome (CMetS) is the name for a clustering of interconnected metabolic factors that increase the risk for the development of cardiovascular disease, other forms of atherosclerotic diseases, and type 2 diabetes mellitus $(\mathrm{T} 2 \mathrm{DM})[5,6 \bullet]$. The prevalence of CMetS varies and depends on the criteria used in different definitions, as well as the composition (sex, age, race, and ethnicity) of the population studied [7]. Metabolic risk factors that cluster in the syndrome include insulin resistance (IR), elevated 
blood pressure (BP), impaired glucose tolerance, central obesity, and dyslipidemia. Other abnormalities, such as chronic proinflammatory and prothrombotic states, as well as oxidative stress, have been added to the syndrome, making its definition even more complex.

Besides the many components and clinical implications of CMetS, there are hitherto no universally accepted pathogenetic mechanisms or diagnostic criteria [7]. Following the initial definition of syndrome $\mathrm{X}$ by Reaven [8], many international organizations and expert groups, such as the World Health Organization (WHO), the European Group for the Study of IR, the National Cholesterol Education Program Adult Treatment Panel III (NCEP:ATPIII), the American Association of Clinical Endocrinologists, the International Diabetes Federation (IDF), and the American Heart Association/National Heart, Lung, and Blood Institute, have used different parameters to define CMetS; each definition focuses mainly on a specific aspect of the cluster (eg, glucose for WHO definition, central obesity for the IDF one, dyslipidemia and other common cardiovascular risk factors for the NCEP:ATPIII definition) [6•]. Furthermore, the debate as to whether CMetS represents a specific syndromic entity, or whether it should be considered only a frequent association of independent cardiovascular risk factors is still unresolved. Therefore, some authors have suggested that the components of the syndrome should be evaluated and treated without regard to whether a patient meets the criteria for diagnosis of the CMetS [9]. However, independent of the diagnostic criteria used, CMetS has a high and increasing prevalence in all Western societies, mostly due to the growing obesity epidemic $[6 \bullet, 7]$. In the United States, according to the National Health and Examination Survey (NHANES) 2003 to 2006, approximately $34 \%$ of people studied met the NCEP:ATPIII criteria for CMetS, with a significant increase compared with previous surveys [10]. The more restrictive WHO criteria showed nearly the same prevalence of CMetS, whereas the IDF definition, which adopted a lower cutoff point for waist circumference, estimated an even higher prevalence [11]. Individuals with CMetS, independently of the diagnostic criteria used, have an increased risk for the development of cardiovascular diseases and associated mortality, as confirmed by epidemiologic and prospective studies [12-15] and by a recent meta-analysis [16 $]$. Although CMetS includes a constellation of cardiovascular, renal, metabolic, prothrombotic, and inflammatory abnormalities, the two major interacting features that are the core and the hallmark of the syndrome are IR/hyperinsulinemia/reduced peripheral glucose utilization and visceral obesity.

Although it is apparent that an interaction between genetic and environmental factors may contribute to the pathophysiology of CMetS, many aspects underlying the abnormalities and physiologic disturbances of the syndrome remain unclear. $\mathrm{Mg}$ has been suggested to play a key role in the pathogenesis of CMetS, as confirmed by many experimental, clinical, and epidemiologic studies that have shown a clear link between Mg status and any individual component included in the constellation [1].

\section{Magnesium and the Cardiometabolic Syndrome Components}

\section{Magnesium and Hypertension}

$\mathrm{Mg}$ ion, although not directly involved in the biochemical process of contraction, modulates vascular smooth muscle tone by affecting calcium ion concentrations. In particular, $\mathrm{Mg}$ regulates the activity of many plasma membrane and cellular ion transport pump mechanisms that maintain the critical cytosolic concentrations of calcium and sodium, hence affecting baseline tension, vascular tone, and responsiveness to pressor agents [17]. Experimental dietary $\mathrm{Mg}$ deficiency has been associated with vasoconstriction, frank hypertension, potentiated atherosclerosis, increased thromboxane synthesis, and IR, all conditions frequently associated with the CMetS $[18,19]$. Epidemiologic studies have suggested an inverse relationship between $\mathrm{Mg}$ intake and $\mathrm{BP}$, with lower dietary $\mathrm{Mg}$ intake being an independent predictor of hypertension [20]. In experimental and in human hypertension, decreased $\mathrm{Mg}$ levels have been reported in several tissues (eg, heart, lungs, kidney, bone, skeletal muscle, blood vessels, and brain) and cell types (eg, vascular smooth muscle cells, fibroblasts, erythrocytes, platelets, and lymphocytes), all confirming the profound alterations of Mg metabolism in hypertensive disease [1, 21-23]. Individuals with essential hypertension have consistently lower concentrations of intracellular free $\mathrm{Mg}$ (Mgi) than normotensive controls, and a strong, continuous inverse relationship is present between Mgi and the height of BP; that is, the lower the Mgi, the higher the BP, confirming the existence of a link between $\mathrm{Mg}$ depletion and human essential hypertension [21-23]. Metabolic conditions, including hypertension, CMetS, and T2DM, share a common altered intracellular environment characterized at least in part by suppressed Mgi levels and reciprocally elevated cytosolic calcium [23]. Mgi levels are related not only to the height of BP but also to the presence of peripheral IR [24], and alterations of $\mathrm{Mg}$ metabolism have been suggested as one of the pathogenic mechanisms contributing to the development of IR and CMetS [1, 24-26]. Moreover, the common alterations of intracellular ionic species in different IR conditions support the concept of an ionic basis underlying the frequent coincidence of the different clinical conditions associated with the CMetS. Altered levels of Mgi also have been found to be associated with structural indices of the cardiovascular system. Suppressed Mgi levels are associated 
with increased echocardiographically measured posterior wall thickness and left ventricular mass index in hypertensive individuals [27]. Similarly, aortic distensibility determined by MRI in healthy and hypertensive humans was closely and positively related to levels of Mgi measured in situ in brain and skeletal muscle tissue by ${ }^{31} \mathrm{P}$-nuclear magnetic resonance (NMR) spectroscopic techniques - the more suppressed the Mgi, the stiffer (less distensible) the aorta [28] $\mathrm{Mg}$ deficiency is also associated with impaired endothelial-mediated vasorelaxation, and oral $\mathrm{Mg}$ supplementation has been shown to improve endothelial function in patients with coronary artery disease [29] and in hypertensive diabetic individuals [30॰].

$\mathrm{Mg}$ metabolism is also linked to the renin-angiotensinaldosterone system (RAAS). In high renin hypertensive individuals, serum ionized $\mathrm{Mg}$ tends to be lower and $\mathrm{Mg}$ supplementation decreases AngII-stimulated production and aldosterone release [31, 32]. These actions of Mg may help explain the relationship with other CMetS components, also connected to the RAAS (IR, increased oxidative stress, reduced nitric oxide bioavailability, and increased synthesis of proinflammatory cytokines [see below]). Mg also modulates sympathetic nervous system activity. An increase in BP together with an increase in catecholamine excretion and renal sympathetic activity have been shown in Mg-deficient rats [33].

$\mathrm{Mg}$ was first recommended to lower BP in patients with malignant hypertension more than 85 years ago, as early as 1925 [34]. However, a consistent, reproducible effect of oral Mg supplementation on BP (except in preeclampsia) is still to be confirmed in essential hypertension [26]. Mg supplementation has been shown to decrease BP in many, but not all clinical studies [35-37], and a focused, large clinical trial is still lacking.

Magnesium, Glucose Intolerance, Insulin Resistance, and Diabetes

$\mathrm{Mg}$ ion plays a key role in regulating insulin actions and insulin-mediated glucose uptake. $\mathrm{Mg}$ is a necessary cofactor in more than 300 enzymatic reactions, including all the ratelimiting enzymes of glycolysis, and specifically in all phosphorylation processes and in all reactions that involve adenosine triphosphate (ATP) utilization and transfer. $\mathrm{Mg}$ deficiency may result in disorders of insulin receptor tyrosine kinase activity as well as all other protein kinases in the insulin signaling, events related to the development of postreceptor IR and decreased cellular glucose utilization [1]. Measurements of intracellular free $\mathrm{Mg}$ concentrations using ${ }^{31} \mathrm{P}-\mathrm{NMR}$ have revealed that Mgi concentrations are in the 100 to $300 \mathrm{nM}$ range, which is close to the dissociation constant of many enzymatic systems using ATP or phosphate transfer; this confirms the clinical significance of $\mathrm{Mg}$ deficiency because of its crucial role as cofactor in many enzymatic reactions regulating glucose metabolism. In turn, because tissue $\mathrm{Mg}$ uptake is regulated by insulin, impairment of this process by CMetS-associated IR may cause or exacerbate intracellular Mg deficiency. The hypothesis that alterations in $\mathrm{Mg}$ metabolism may induce and/or exacerbate IR is confirmed by data in both humans and experimental animals, showing that dietary-induced $\mathrm{Mg}$ deficit is correlated with IR, lower fasting insulin concentrations, and insulin responses to an oral glucose load [1]. Intracellular $\mathrm{Mg}$ levels have been found to quantitatively and inversely predict the fasting and postglucose levels of hyperinsulinemia, peripheral insulin sensitivity, and systolic and diastolic BP $[1,3,21-24,26]$. Specifically, fasting insulin levels, the integrated insulinemic response to a standard oral glucose tolerance test, and the steady-state plasma glucose response to insulin infusion and indices of peripheral insulin sensitivity derived from euglycemic hyperinsulinemic clamps all have been found to be inversely related to $\mathrm{Mg}$ levels, whether measured as Mgi in situ in the brain, free or total $\mathrm{Mg}$ in peripheral red cells, or even as circulating $\mathrm{Mg}$. Furthermore, inverse relations have been observed between steady-state fasting levels of Mgi and 1) fasting blood glucose; 2) BP; 3 ) glycated hemoglobin $\left(\mathrm{HbAl}_{\mathrm{c}}\right)$; and 4) the glycemic and insulinemic response to oral glucose loading in healthy, hypertensive, and diabetic individuals - the lower the Mgi, the higher the BP and the hyperinsulinemic response to oral glucose loading [1, 3, 21-24, 26].

There is evidence consistently showing a deficiency in intracellular, in serum total, and/or in serum ionized $\mathrm{Mg}$ in patients with T2DM and/or the CMetS [1, 23, 38, 39]. A deficient $\mathrm{Mg}$ status may be a secondary consequence or may precede and cause IR and altered glucose tolerance. Among the mechanisms that may favor $\mathrm{Mg}$ depletion in the CMetS, the most important are low $\mathrm{Mg}$ intake and increased $\mathrm{Mg}$ urinary loss, while dietary $\mathrm{Mg}$ absorption and retention seem to remain unaffected. With regard to low Mg intake, changes in dietary habits in the direction of a Westernized pattern have resulted in a frequent occurrence of $\mathrm{Mg}$ intake below the recommended daily allowances. Hyperinsulinemia associated with CMetS may contribute to urinary $\mathrm{Mg}$ depletion, while the reduced insulin sensitivity itself may affect $\mathrm{Mg}$ transport. All together, independent of the cause of poor plasma and intracellular $\mathrm{Mg}$ content, $\mathrm{Mg}$ depletion is a contributor to further derangement of IR [1]. Reduced serum $\mathrm{Mg}$ levels are associated with an increased risk of developing glucose intolerance, CMetS, and T2DM [40]. The frequent inadequacy of $\mathrm{Mg}$ metabolism with aging has been suggested to play a role in the increased incidence of age-associated vascular and metabolic conditions such as hypertension, atherosclerosis, T2DM, and CMetS [41 •, $42 \bullet, 43-45]$. All together, regardless of the cause of poor plasma and intracellular $\mathrm{Mg}$ content, a depletion of $\mathrm{Mg}$ seems to contribute to an impairment of insulin sensitivity. 
Mg deficiency, which may take the form of a chronic, latent $\mathrm{Mg}$ deficit rather than a clinically evident hypomagnesemia, is crucial because of the previously described key role of $\mathrm{Mg}$ as a cofactor in many enzymatic reactions regulating glucose metabolism. Thus, deficient Mg status may not just be a secondary consequence of diabetes but may precede and contribute itself to the development of IR and altered glucose tolerance. $\mathrm{Mg}$ depletion promotes tissutal IR and altered vascular tone, suggesting a possible mechanism underlying the coincidence among apparently disparate clinical conditions of IR. We have suggested a role for $\mathrm{Mg}$ deficit as a unifying mechanism of conditions associated with IR, including hypertension, T2DM, and CMetS (Fig. 1) [1, 26, 45]. The hypothesis that alterations in $\mathrm{Mg}$ metabolism induce IR is confirmed by data in experimental animals and humans showing that dietaryinduced Mg deficiency is correlated with IR. A Mg-deficient diet in sheeps was associated with a significant impairment in insulin-mediated glucose uptake [46]. Higher $\mathrm{Mg}$ intake is associated with lower fasting insulin concentrations among women without diabetes [47], and a significant negative correlation is present between total dietary $\mathrm{Mg}$ intake and the insulin responses to an oral glucose tolerance test [48]. Rats fed a low-Mg diet showed a significant increase in blood glucose and triglyceride levels [49]. The effects of dietaryinduced $\mathrm{Mg}$ deficiency on glucose disposal, glucosestimulated insulin secretion, and insulin action on skeletal muscle were studied in rats fed a low-Mg-containing diet. $\mathrm{Mg}$ depletion provoked a deleterious effect on glucose metabolism due to an impairment of both insulin secretion and action [50]. The IR observed in the skeletal muscles of Mgdeficient rats was linked, at least in part, to a defective tyrosine kinase activity of insulin receptors [51].
Magnesium and Other Components of the Cardiometabolic Syndrome Constellation (Dyslipidemia, Visceral Adiposity, Coagulation Factors)

The relationship between $\mathrm{Mg}$ status and lipid profile is less clear than that between BP and IR described above, with studies presenting conflicting results depending on the population examined $[52,53] . \mathrm{Mg}$ is a modulator of HMG-CoA reductase, which catalyzes the rate-limiting step in cholesterol synthesis. In vitro studies have shown that increasing $\mathrm{Mg}$ concentration in the bathing solution attenuates HMGCoA reductase activity [54], and rats fed a Mg-deficient diet show increased serum triglycerides and reduced highdensity lipoprotein cholesterol, together with reduced serum activity of lipoprotein lipase [55]. Several other studies have examined the effect of $\mathrm{Mg}$ supplementation on lipid levels and have shown a reduction in serum triglyceride levels [56-58] or no effect on the lipids examined [59]. Visceral adiposity is another major component of the CMetS associated with a state of IR and impaired glucose tolerance [5, 6•, 7, 52]. Mg deficiency status was found in Zucker obese rats [60] and in clinical obesity in individuals with IR [61]. In patients with T2DM, Corica et al. [38] found a strong correlation between serum ionized $\mathrm{Mg}$ and several components of the CMetS (plasma triglycerides, waist circumference, and microalbuminuria). Mg deficiency may also contribute to the development of IR in obese children [62, 63]. Mazur et al. [60] reported that feeding obese animals a high-Mg diet reduced body weight, improved insulin sensitivity, normalized serum lipids, and corrected plasma $\mathrm{Mg}$ content.

An increased platelet reactivity and a prothrombotic state (increased levels of plasminogen activator inhibitor-1 [PAI-1],

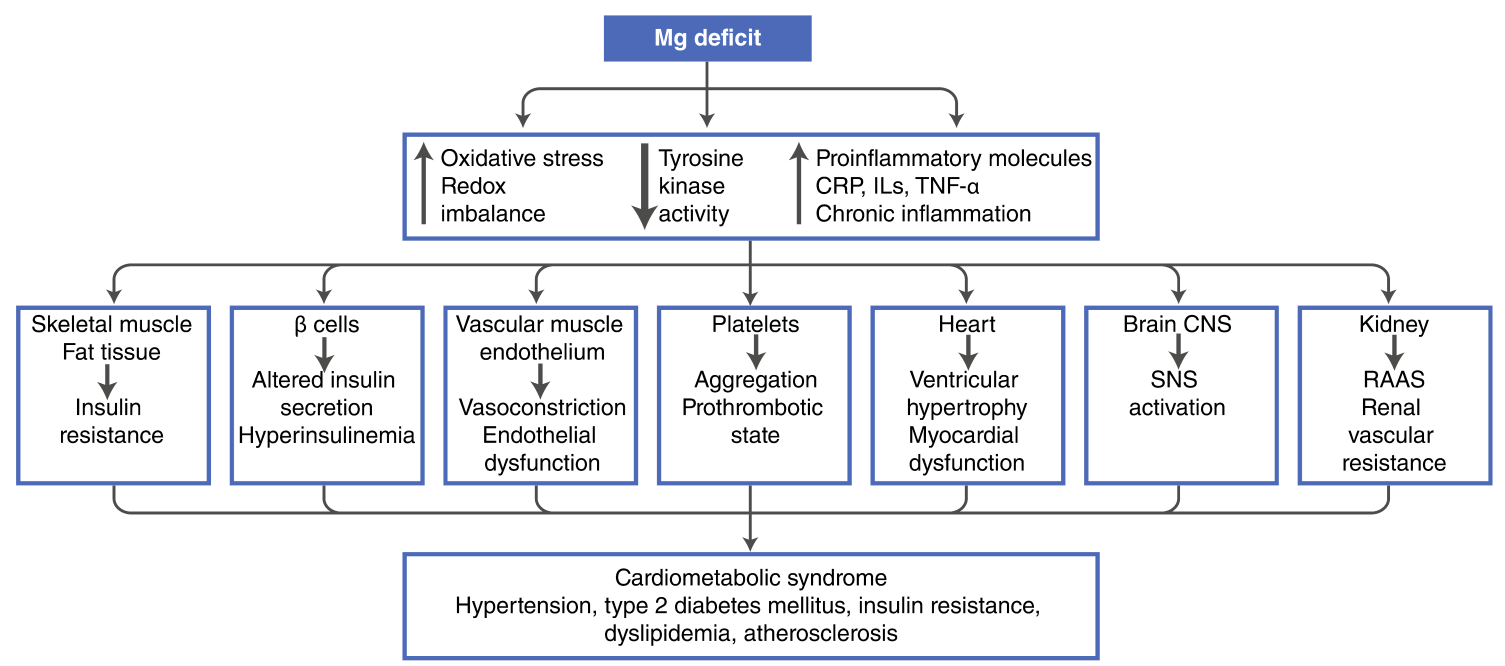

Fig. 1 Overall hypothesis in which chronic magnesium $(\mathrm{Mg})$ deficit has been proposed as a link to help explain the clinical coincidence of hypertension, type 2 diabetes mellitus, insulin resistance, dyslipidemia, and atherosclerosis in the cardiometabolic syndrome. CNS, central nervous system; CRP, C-reactive protein; IL, interleukin; RAAS, renin-angiotensin-aldosterone system; SNS, sympathetic nervous system; TNF, tumor necrosis factor 
fibrinogen, and other coagulation factors) are commonly associated with CMetS. Nadler et al. [19, 64] suggested that intracellular $\mathrm{Mg}$ deficiency may cause increased platelet reactivity and thromboxane synthesis. $\mathrm{Mg}$ therapy may have antithrombotic effects and has been shown to decrease platelet aggregation $[65,66]$.

Magnesium, Inflammation, and Oxidative Stress

An increased inflammatory state is frequently associated with glucose disorders and metabolic diseases [67, 68]. Inflammation and oxidative stress have been proposed as the possible link between $\mathrm{Mg}$ deficit and IR/CMetS [69-72]. More generally, chronic hypomagnesaemia and conditions commonly connected with $\mathrm{Mg}$ deficiency, such as T2DM and aging, are associated with increased free radical formation and subsequent damage to cellular processes. Poor $\mathrm{Mg}$ status may trigger the development of a low-grade chronic inflammatory state and an increased production of free oxygen radicals. Several experimental and clinical studies have shown that $\mathrm{Mg}$ deprivation causes marked elevation of proinflammatory molecules, causing excessive production and release of tumor necrosis factor (TNF)- $\alpha$, interleukin (IL)-1, IL-6, vascular cell adhesion molecule-1, and PAI-1; increased circulating inflammatory cells; and increased hepatic production and release of acutephase proteins (ie, complement, $\alpha 2$-macroblobulin, fibrinogen) [73-77]. Experimental studies in rats have shown that $\mathrm{Mg}$ deficiency induces a chronic impairment of redox status associated with inflammation, which could contribute to increased oxidized lipids and may promote IR, $\beta$-cell dysfunction, hypertension, and vascular disorders [1, 69-72, 78]. In humans, clinical data have shown that low serum $\mathrm{Mg}$ levels as well as inadequate dietary $\mathrm{Mg}$ are strongly related to low-grade systemic inflammation. Using the 1999 to 2000 NHANES database, King et al. [69] found that dietary $\mathrm{Mg}$ intake was inversely related to serum $\mathrm{C}$ reactive protein (CRP) levels. Among the $70 \%$ of the population not taking supplements, $\mathrm{Mg}$ intake below the recommended daily allowance was significantly associated with a higher risk of having elevated CRP [69]. Data from the Women's Health Study have shown that Mg intake is inversely related to systemic inflammation measured by CRP concentrations and with the prevalence of the CMetS in adult women [72]. Other studies have confirmed an inverse relationship among $\mathrm{Mg}$ intake, serum $\mathrm{Mg}$, and TNF- $\alpha$, IL-6, and CRP levels [70, 71]. In a cross-sectional study, a higher TNF- $\alpha$ concentration was inversely correlated with serum $\mathrm{Mg}$, and in a multivariate analysis, those individuals with the lowest serum $\mathrm{Mg}$ were $80 \%$ more likely to have higher circulating levels of TNF- $\alpha$ [71]. In men from the Health Professionals' Follow-Up study, higher $\mathrm{Mg}$ intake was associated with higher adiponectin levels
[79]. In experimental animal models and in humans, $\mathrm{Mg}$ deficiency has been associated with increased oxidative stress and decreased antioxidant defense, due at least in part to increased inflammation parameters [78, 80-82]. More generally, chronic hypomagnesaemia and conditions commonly associated with Mg deficiency, such as T2DM and aging, are associated with an increase in free radical formation, with subsequent damage to cellular processes [1, 80, 81]. Previous studies have shown convincingly that $\mathrm{Mg}$ deficiency results in increased production of oxygenderived free radicals in various tissues, increased free radical-elicited oxidative tissue damage, increased production of superoxide anion by inflammatory cells, decreased antioxidant enzyme expression and activity, decreased cellular and tissue antioxidant levels, and increased oxygen peroxide $[78,82]$. In experimental diabetes, a decreased intracellular $\mathrm{Mg}$ level and increased $\mathrm{Mg}$ urinary excretion were associated with increased plasma malondialdehyde and a decreased expression of hepatic superoxide dismutase (SOD) and glutathione S-transferase, with all these effects being corrected by $\mathrm{Mg}$ supplementation [83]. $\mathrm{Mg}$ deficiency in rats also causes decreased hepatic glutathione, SOD, and vitamin $\mathrm{E}$ together with increased lipid peroxidation and malondialdehyde levels secondary to upregulated NADPH oxidase acitivity [84]. Furthermore, $\mathrm{Mg}$ itself may possess antioxidant properties, scavenging oxygen radicals, possibly by affecting the rate of spontaneous dismutation of the superoxide ion [82]. Intervention studies in animal models of $\mathrm{Mg}$ deficiency have also provided convincing evidence of the link among $\mathrm{Mg}$, inflammation, and oxidative stress. In stroke-prone spontaneously hypertensive rats, $\mathrm{Mg}$ deficiency results in marked increases in systolic BP, blunted endothelial function, superoxide accumulation, and mitogen-activated protein kinase activation, all of which were attenuated with a SOD mimetic [85]. Intervention studies have shown that treatment with antioxidant therapies (eg, vitamin $\mathrm{C}$, vitamin $\mathrm{E}$, and glutathione) improves insulin sensitivity in diabetic individuals. Improvement in endogenous antioxidant capacity (GSH:GSSG ratio) and blunting of oxidative stress (decreased GSH:GSSG, increased lipohydroperoxides, increased TBARS, and decreased total antioxidant capacity) were associated with improved cellular Mg homeostasis and improved whole body glucose disposal $[86,87]$. All together, data are consistent with a role of $\mathrm{Mg}$ deficiency in reducing antioxidant capacity and in promoting oxidative stress, inflammation, and lipid oxidation, and thus with a role of oxidative stress and inflammation in the $\mathrm{Mg}$ deficiency-related development of IR, CMetS, and T2DM [1, 26, 45].

Dietary Magnesium and the Cardiometabolic Syndrome

Data from several epidemiologic studies have confirmed a clear link among dietary $\mathrm{Mg}$ status, T2DM, and CMetS, 
suggesting that increased $\mathrm{Mg}$ consumption is associated with a reduced development of T2DM [88] and CMetS $[72,89]$. In a prospective study of almost 85,000 women from the Nurses' Health Study and the Health Professionals' Follow-Up Study, the relative risk of developing T2DM for women in the highest quintile of $\mathrm{Mg}$ consumption was 0.68 when compared with women in the lowest quintile [88]. In more than 11,000 middle-aged women from the Women's Health Study, Song et al. [72] reported an inverse association between dietary $\mathrm{Mg}$ intake and CMetS prevalence. In a longitudinal analysis of 4,637 young adults within the CARDIA (Coronary Artery Risk Development in Young Adult Men) study, He et al. [89] found that Mg intake was inversely related to incident $\mathrm{CMetS}$, each of its components, and fasting insulin levels. In the Women's Health Study, a cohort of 39,345 US women older than 45 years of age were observed for an average of 6 years; a significant inverse association was found between $\mathrm{Mg}$ intake and the risk of developing T2DM, further supporting a protective role of high $\mathrm{Mg}$ intake in reducing the risk of becoming diabetic [90]. High Mg intake also lowered the concentrations of markers of systemic inflammation and endothelial dysfunction [91•].

Thus, data suggest that the use of Mg supplements may be a potential tool for the prevention of T2DM and the CMetS [92]. The effects of Mg supplements on the metabolic profile of diabetic individuals are controversial, with benefits having been found in some [93], but not all clinical studies [94]. Differences in baseline $\mathrm{Mg}$ status, age, and variability of diabetic clinical control, duration, and complications may explain the differences among studies. A metaanalysis of nine randomized, double-blind, controlled studies, indicated that oral $\mathrm{Mg}$ supplementation for 3 months was effective in lowering fasting serum glucose levels in T2DM patients [95], in accordance with the physiologic role of $\mathrm{Mg}$, to modulate cellular glucose utilization and insulin signaling [1]. The high content of $\mathrm{Mg}$ in whole grains has suggested that $\mathrm{Mg}$ may mediate their favorable impact on insulin sensitivity [96]. Oral Mg supplementation has been suggested to be beneficial with regard to fasting and postprandial glucose levels and insulin sensitivity in type 2 diabetics with a severe Mg deficit [3, 93]. Among nondiabetic, apparently healthy individuals, there is also some evidence of a relatively small but significant beneficial effect of $\mathrm{Mg}$ supplementation on insulin sensitivity [97].

\section{Conclusions}

$\mathrm{Mg}$ is emerging as a key player in CMetS pathogenesis, as evidenced by the numerous experimental, clinical, and epidemiologic studies delineating a clear link between $\mathrm{Mg}$ status and each of the CMetS components (Fig. 1).
Notwithstanding the antihypertensive, anti-inflammatory, antioxidant properties of $\mathrm{Mg}$, it is crucial to remember the strong and unquestionable pathophysiologic link between $\mathrm{Mg}$ and insulin sensitivity and action. That no large clinical trial with $\mathrm{Mg}$ supplementation has been specifically focused on individuals with $\mathrm{Mg}$ deficit may help explain the discrepancy between the epidemiologic evidence of a clear role of $\mathrm{Mg}$ deficit in the pathophysiology of the CMetS and the still uncertain benefit of oral supplemental Mg on IR. Longterm prospective studies evaluating the effects of $\mathrm{Mg}$ supplements on the development of CMetS and/or T2DM in populations with $\mathrm{Mg}$ deficiency are still needed to narrow this gap.

Disclosure No potential conflicts of interest relevant to this article were reported.

\section{References}

Papers of particular interest, published recently, have been highlighted as:

- Of importance

•- Of major importance

1. Barbagallo M, Dominguez LJ: Magnesium metabolism in type 2 diabetes mellitus, metabolic syndrome and insulin resistance. Arch Biochem Biophys 2007, 458:40-47.

2. Saris NE, Mervaala E, Karppanen H, et al.: Magnesium. An update on physiological, clinical and analytical aspects. Clin Chim Acta 2000, 294:1-26.

3. Paolisso G, Barbagallo M: Hypertension, diabetes mellitus, and insulin resistance: the role of intracellular magnesium. Am J Hypertens 1997, 10:346-355.

4. Barbagallo M, Gupta RK, Resnick LM: Cellular ionic effects of insulin in normal human erythrocytes: a nuclear magnetic resonance study. Diabetologia 1993, 36:146-149.

5. Eckel RH, Grundy SM, Zimmet PZ: The metabolic syndrome. Lancet 2005; 365: 1415-28.

6. - Kassi E, Pervanidou P, Kaltsas G, Chrousos G.: Metabolic syndrome: definitions and controversies. BMC Medicine 2011, 9:48. The controversies on existing definitions of metabolic syndrome are described here in addition to the need to develop uniform criteria for diagnosis.

7. Cornier MA, Dabelea D, Hernandez TL, et al: The metabolic syndrome. Endocr Rev 2008, 29:777-822.

8. Reaven GM: Banting lecture 1988. Role of insulin resistance in human disease. Diabetes 1988, 37:1595-1607.

9. Kahn R, Buse J, Ferrannini E, et al.: The metabolic syndrome: time for a critical appraisal. Joint statement from the American Diabetes Association and the European Association for the Study of Diabetes. Diabetologia 2005, 48:1684-99.

10. Ervin RB: Prevalence of metabolic syndrome among adults 20 years of age and over, by sex, age, race and ethnicity, and body mass index: United States, 2003-2006. Natl Health Stat Report 2009, 13:1-7. 
11. Ford ES, Li C, Zhao G: Prevalence and correlates of metabolic syndrome based on a harmonious definition among adults in the US. J Diabetes 2010, 2:180-193.

12. McNeill AM, Rosamond WD, Girman CJ, et al.: The metabolic syndrome and 11-year risk of incident cardiovascular disease in the atherosclerosis risk in communities study. Diabetes Care 2005, 28:385-390.

13. Hunt KJ, Resendez RG, Williams K, et al.: National Cholesterol Education Program versus World Health Organization metabolic syndrome in relation to all-cause and cardiovascular mortality in the San Antonio Heart Study. Circulation 2004, 110:1251-1257.

14. Lakka HM, Laaksonen DE, Lakka TA, et al.: The metabolic syndrome and total and cardiovascular disease mortality in middle-aged men. JAMA 2002, 288:2709-2716.

15. Ford ES: Risks for all-cause mortality, cardiovascular disease, and diabetes associated with the metabolic syndrome: a summary of the evidence. Diabetes Care 2005, 28:1769-1778.

16. - Mottillo S, Filion KB, Genest J, et al.: The metabolic syndrome and cardiovascular risk a systematic review and meta-analysis. J Am Coll Cardiol 2010, 56:1113-1132. This a systematic review and meta-analysis of the cardiovascular risk associated with the metabolic syndrome, showing that it is associated with a twofold increase in cardiovascular outcomes and a 1.5-fold increase in allcause mortality.

17. Altura BM, Altura BT, Carella A: Magnesium deficiency-induced spasms of umbilical vessels: relation to preeclampsia, hypertension, growth retardation. Science 1983, 221:376-378.

18. Altura BM, Altura BT, Gebrewold A, et al: Magnesium deficiency and hypertension: correlation between magnesium-deficient diets and microcirculatory changes in situ. Science 1984, 223:13151317.

19. Nadler JL, Buchanan T, Natarajan R, et al.: Magnesium deficiency produces insulin resistance and increased thromboxane synthesis. Hypertension 1993, 21:1024-1029

20. Joffres MR, Reed DM, Yano K: Relationship of magnesium intake and other dietary factors to blood pressure: the Honolulu heart study. Am J Clin Nutr 1987, 45:469-475.

21. Resnick LM, Gupta RK, Laragh JH: Intracellular free magnesium in erythrocytes of essential hypertension: relation to blood pressure and serum divalent cations. Proc Natl Acad Sci U S A 1984, 81:6511-6515.

22. Resnick LM, Barbagallo M, Bardicef M, et al.: Cellular-free magnesium depletion in brain and muscle of normal and preeclamptic pregnancy: a nuclear magnetic resonance spectroscopic study. Hypertension 2004, 44:322-326.

23. Resnick LM, Gupta RK, Bhargava KK, et al.: Cellular ions in hypertension, diabetes, and obesity. A nuclear magnetic resonance spectroscopic study. Hypertension 1991, 17:951-957.

24. Resnick LM, Gupta RK, Gruenspan H, et al.: Hypertension and peripheral insulin resistance. Possible mediating role of intracellular free magnesium. Am J Hypertens 1990, 3:373-379.

25. Belin RJ, He K: Magnesium physiology and pathogenic mechanisms that contribute to the development of the metabolic syndrome. Magnesium Research 2007, 20:107-129.

26. Barbagallo M, Dominguez LJ: Magnesium metabolism in hypertension and type 2 diabetes mellitus. Am J Therapeutics 2007, 14:375-385.

27. Barbagallo M, Gupta RK, Resnick LM: Cellular ions in NIDDM: relation of calcium to hyperglycemia and cardiac mass. Diabetes Care 1996, 19:1393-1398.

28. Resnick LM, Militianu D, Cunnings AJ, et al.: Pulse waveform analysis of arterial compliance: relation to other techniques, age, and metabolic variables. Am J Hypertens 2000, 13:1243-1249.

29. Shechter M, Sharir M, Labrador MJP, et al.: Oral magnesium therapy improves endothelial function in patients with coronary artery disease. Circulation 2000, 102:2353-2358.
30. • Barbagallo M, Dominguez LJ, Galioto A, et al.: Oral magnesium supplementation improves vascular function in elderly diabetic patients. Magnes Res 2010, 23:131-137. The present study suggests that oral Mg improves endothelial function in diabetic older adults. Mg ions influence vascular tone and responsiveness and are cofactors for acetylcholine-induced, endothelium-dependent relaxation. $\mathrm{Mg}$ intervention resulted in a significant improvement in the postischemic, endothelial-dependent, flow-mediated dilation.

31. Resnick LM, Laragh JH, Sealey JE, et al.: Divalent cations in essential hypertension. Relations between serum ionized calcium, magnesium, and plasma renin activity. N Engl J Med 1983, 309: 888-891.

32. Ichihara A, Suzuki H, Saruta T: Effects of magnesium on the reninangiotensin-aldosterone system in human subjects. J Lab Clin Med 1993, 122: 432-440.

33. Murasato Y, Harada Y, Ikeda M, et al.: Effect of magnesium deficiency on autonomic circulatory regulation in conscious rats. Hypertension 1999, 34: 247-252.

34. Blackfan K, Hamilton B: Uremia in acute glomerular nephritis: the cause and treatment in children. Med Surg J 1925, 193:617-628.

35. Kawano Y, Matsuoka H, Takishita S, et al.: Effects of magnesium supplementation in hypertensive patients: assessment by office, home, and ambulatory blood pressures. Hypertension 1998; 32: 260-265.

36. Dyckner T, Wester PO: Effect of magnesium on blood pressure. Br Med J 1983, 286: 1847-1849.

37. Cappuccio FP, Markandu ND, Beynon GW, et al.: Lack of effect of oral magnesium on high blood pressure: a double blind study. $\mathrm{Br}$ Med J 1985, 291:235-238.

38. Corica F, Corsonello A, Ientile R, et al.: Serum ionized magnesium levels in relation to metabolic syndrome in type 2 diabetic patients. J Am Coll Nutr 2006, 25:210-215.

39. Guerrero-Romero F, Rodriguez-Moran M: Low serum magnesium levels and metabolic syndrome. Acta Diabetol 2002, 39: 209-213.

40. Kao WH, Folsom AR, Nieto FJ, et al.: Serum and dietary magnesium and the risk for type 2 diabetes mellitus: the Atherosclerosis Risk in Communities Study. Arch Intern Med. 1999, 159:21512159.

41. • Barbagallo M, Dominguez LJ: Magnesium and aging. Current Pharmaceutical Design 2010, 16:832-839. Mg deficiency reduces the threshold antioxidant capacity of the aging organism and its resistance to free radical damage. Chronic Mg deficiency results in excessive production of oxygen-derived free radicals and low-grade inflammation, conditions common in aging and the CMetS. Mg deficits are proposed as one of the physiopathological links that may help explain the interactions among inflammation, oxidative stress with the aging process, and many age-related diseases.

42. •- Barbagallo M, Belvedere M, Dominguez LJ: Magnesium homeostasis and aging. Magnes Res 2009, 22:235-246. Cause and mechanisms of $\mathrm{Mg}$ deficits with aging are described here. Chronic $\mathrm{Mg}$ deficiency, observed in the older adult population, has been linked to an increased risk of many preclinical and clinical outcomes, including hypertension, stroke, atherosclerosis, ischemic heart disease, cardiac arrhythmias, glucose intolerance, IR, $T 2 D M$, endothelial dysfunction, vascular remodeling, alterations in lipid metabolism, platelet aggregation/thrombosis, inflammation, oxidative stress, and cardiovascular mortality — all conditions present in the CMetS.

43. Barbagallo M, Gupta R, Dominguez LJ et al.: Cellular ionic alterations with aging: relation to hypertension and diabetes. J Am Geriatr Soc 2000, 48:1111-1116.

44. Barbagallo M, Resnick LM, Dominguez LJ, et al.: Diabetes mellitus, hypertension and ageing: the ionic hypothesis of ageing and cardiovascular-metabolic diseases. Diabetes Metab 1997, 23:281-294. 
45. Barbagallo M, Dominguez LJ, Galioto A, et al.: Role of magnesium in insulin action, diabetes, and cardio-metabolic syndrome $\mathrm{X}$. Mol Aspects Med 2003, 24:39-52.

46. Matsunobu S, Terashima Y, Senshu T, et al.: Insulin secretion and glucose uptake in hypomagnesemic sheep fed a low magnesium, high potassium diet. J Nutr Biochem 1990, 1:167-171.

47. Fung TT, Manson JE, Solomon CG, et al.: The association between magnesium intake and fasting insulin concentration in healthy middle-aged women. J Am Coll Nutr 2003, 22:533-538.

48. Humphries S, Kushner H, Falkner B: Low dietary magnesium is associated with insulin resistance in a sample of young, nondiabetic black Americans. Am J Hypertens 1999, 12:747-756.

49. Chaudhary DP, Boparai RK, Sharma R, et al.: Studies on the development of an insulin resistant rat model by chronic feeding of low magnesium high sucrose diet. Magnes Res 2004, 17:293300 .

50. Venu L, Padmavathi IJ, Kishore YD, et al.: Long-term effects of maternal magnesium restriction on adiposity and insulin resistance in rat pups. Obesity 2008, 16:1270-1276.

51. Suárez A, Pulido N, Casla A, et al.: Impaired tyrosine-kinase activity of muscle insulin receptors from hypomagnesaemic rats. Diabetologia 1995, 38:1262-1270.

52. Randell EW, Mathews M, Gadag V, et al.: Relationship between serum magnesium values, lipids and anthropometric risk factors. Atherosclerosis 2008, 196:413-419.

53. Corsonello A, Perticone F, Barbagallo M, et al.: Serum magnesium and lipids: more clarity is needed. Atherosclerosis 2007; 192:233234.

54. Field FJ, Henning B, Mathur SN: In vitro regulation of 3-hydroxy-3methylglutarylcoenzyme A reductase and acylcoenzyme A: cholesterol acyltransferase activities by phosphorylation-dephosphorylation in rabbit intestine. Biochim Biophys Acta 1984, 802:9-16.

55. Rayssiguier Y, Noe L, Etienne J, et al.: Effect of magnesium deficiency on post-heparin lipase activity and tissue lipoprotein lipase in the rat. Lipids 1991, 26:182-186.

56. Yokota K, Kato M, Lister F, et al.: Clinical efficacy of magnesium supplementation in patients with type 2 diabetes. J Am Coll Nutr 2004, 23:506S-509S

57. Kisters K, Spieker C, Tepel M, et al.: New data about the effects of oral physiological magnesium supplementation on several cardiovascular risk factors (lipids and blood pressure). Magnes Res 1993, 6:355-360.

58. Rasmussen HS, Aurup P, Goldstein K, et al.: Influence of magnesium substitution therapy on blood lipid composition in patients with ischemic heart disease. A double-blind, placebo controlled study. Arch Intern Med 1989, 149:1050-103.

59. Marken PA, Weart CW, Carson DS, et al.: Effects of magnesium oxide on the lipid profile of healthy volunteers. Atherosclerosis 1989, 77:37-42.

60. Mazur A, Gueux E, Remesy C, et al.: Plasma and red blood cell magnesium concentrations in Zucker rats: influence of a high fibre diet. Magnes Res 1989, 2:189-192.

61. Rodriguez-Hernandez H, Gonzalez JL, Rodriguez-Moran M, Guerrero-Romero F: Hypomagnesemia, insulin resistance, and non-alcoholic steatohepatitis in obese subjects. Arch Med Res 2005, 36: 362-366.

62. Celik N, Andiran N, Yilmaz AE: The relationship between serum magnesium levels with childhood obesity and insulin resistance: a review of the literature. J Pediatr Endocrinol Metab 2011, 24:675678.

63. Takaya J, Higashino H, Kotera F, et al.: Intracellular magnesium of platelets in children with diabetes and obesity. Metabolism 2003, 52:468-471.

64. Nadler JL, Malayan S, Luong H, et al.: Intracellular free magnesium deficiency plays a key role in increased platelet reactivity in type II diabetes mellitus. Diabetes Care 1992, 15:835-841.
65. Ravn HB, Vissinger H, Kristensen SD, et al.: Magnesium inhibits platelet activity — an in vitro study. Thromb Haemost 1996, 76:8893.

66. Sheu JR, Hsiao G, Shen MY, et al.: Antithrombotic effects of magnesium sulfate in in vivo experiments. Int J Hematol 2003, 77:414-419.

67. Barzilay J, Abraham L, Heckbert SR, et al.: The relation of markers of inflammation to the development of glucose disorders in the elderly: the Cardiovascular Health Study. Diabetes 2001, 50: 2384-2389.

68. Ford ES, Ajani UA, Mokdad AH: The metabolic syndrome and concentrations of C-reactive protein among U.S. youth. Diabetes Care 2005, 28:878-881.

69. King DE, Mainous AG, Geesey ME, Woolson RF: Dietary magnesium and C-reactive protein. J Am Coll Nutr 2005, 24:166-171.

70. Guerrero-Romero F, Rodriguez-Moran M: Hypomagnesemia, oxidative stress, inflammation, and metabolic syndrome. Diabetes Metab Res Rev 2006, 22:471-476.

71. Rodriguez-Moran M, Guerrero-Romero F: Elevated concentrations of TNF-alpha are related to low serum magnesium levels in obese subjects. Magnes Res 2004, 17:189-196.

72. Song Y, Ridker PM, Manson JE, et al.: Magnesium intake, C-reactive protein, and the prevalence of metabolic syndrome in middle-aged and older U.S. women. Diabetes Care 2005, 28:1438-1444.

73. Weglicki WB, Dickens BF, Wagner TL, et al.: Immunoregulation by neuropeptides in magnesium deficiency: ex vivo effect of enhanced substance $\mathrm{P}$ production on circulation $\mathrm{T}$ lymphocytes from magnesium-deficient mice. Magnes Res 1996, 9:3-11.

74. Kramer JH, Mak IT, Phillips TM, et al.: Dietary magnesium intake influences circulating pro-inflammatory neuropeptide levels and loss of myocardial tolerance to postischemic stress. Exp Biol Med 2003, 228:665-673.

75. Malpuech-Brugere $C$, Nowacki W, et al.: Inflammatory response following acute magnesium deficiency in the rat. Biochim Biophys Acta 2000, 1501: 91-98.

76. Bussiere FI, Tridon A, Zimowska W, et al.: Increase in complement component $\mathrm{C} 3$ is an early response to experimental magnesium deficiency in rats. Life Sci 2003, 73:499-507.

77. Weglicki WB, Phillips TM: Pathobiology of magnesium deficiency: a cytokine /neurogenic inflammation hypothesis. Am J Physiol 1992, 263:R734-737.

78. Blache D, Devaux S, Joubert O, et al.: Long-term moderate magnesium-deficient diet shows relationships between blood pressure, inflammation and oxidant stress defense in aging rats. Free Radic Biol Med 2006, 41:277-284.

79. Qi L, Rimm E, Liu S, et al.: Dietary glycemic index, glycemic load, cereal fiber, and plasma adiponectin concentration in diabetic men. Diabetes Care 2005, 28:1022-1028.

80. Mazur A, Maier JA, Rock E, et al.: Magnesium and the inflammatory response: potential physiopathological implications. Arch Biochem Biophys 2007, 458:48-56.

81. Nasulewicz A, Zimowska W, Bayle D, et al.: Changes in gene expression in the lungs of Mg-deficient mice are related to an inflammatory process. Magnes Res 2004, 17:259-263.

82. Weglicki WB, Bloom S, Cassidy MM, et al.: Antioxidant and the cardiomyopathy of Mg deficiency. Am J Cardiovasc Pathol 1992, $4: 210-216$

83. Hans CP, Chaudhary DP, Bansal DD: Effect of magnesium supplementation on oxidative stress in alloxanic diabetic rats. Magnes Res 2003, 16:13-19.

84. Calviello G, Ricci P, Lauro L, et al.: Mg deficiency induces mineral content changes and oxidative stress in rats. Biochem Mol Biol Int 1994, 32:903-911.

85. Touyz RM, Pu Q, He G, et al.: Effects of low dietary magnesium intake on development of hypertension in stroke-prone spontaneously hypertensive rats: role of reactive oxygen species. J Hypertens 2002, 20:2221-2232. 
86. Barbagallo M, Dominguez LJ, Tagliamonte MR, et al.: Effect of glutathione on red blood cell intracellular magnesium: relation to glucose metabolism. Hypertension 1999, 34:76-82.

87. Barbagallo M, Dominguez LJ, Tagliamonte MR, et al.: Effects of vitamin $\mathrm{E}$ and glutathione on glucose metabolism: role of magnesium. Hypertension 1999, 34: 1002-1006.

88. Lopez-Ridaura R, Willett WC, Rimm EB, et al.: Magnesium intake and risk of type 2 diabetes in men and women. Diabetes Care 2004, 27:134-140.

89. He K, Liu K, Daviglus ML, et al.: Magnesium intake and incidence of metabolic syndrome among young adults. Circulation 2006, 113:1675-1682.

90. Song Y, Manson JE, Buring JE, et al.: Dietary magnesium intake in relation to plasma insulin levels and risk of type 2 diabetes in women. Diabetes Care 2004, 27:59-65.

91. - Chacko SA, Song Y, Nathan L, et al.: Relations of dietary magnesium intake to biomarkers of inflammation and endothelial dysfunction in an ethnically diverse cohort of postmenopausal women. Diabetes Care 2010, 33:304-310. High Mg intake is associated with lower concentrations of markers of systemic inflammation and endothelial dysfunction in postmenopausal women.
92. Guerrero-Romero F, Rodriguez-Moran M: Complementary therapies for diabetes: the case for chromium, magnesium, and antioxidants. Arch Med Res 2005, 36:250-257.

93. Rodriguez-Moran M, Guerrero-Romero F: Oral magnesium supplementation improves insulin sensitivity and metabolic control in type 2 diabetic subjects: a randomized double-blind controlled trial. Diabetes Care 2003, 26:1147-1152.

94. de Valk HW, Verkaaik R, van Rijn HJ, et al.: Oral magnesium supplementation in insulin-requiring type 2 diabetic patients. Diabet Med 1998, 15:503-507.

95. Song Y, He K, Levitan EB, Manson JE, et al.: Effects of oral magnesium supplementation on glycaemic control in type 2 diabetes: a meta-analysis of randomized double-blind controlled trials. Diabet Med 2006, 23:1050-1056.

96. McCarty MF: Magnesium may mediate the favorable impact of whole grains on insulin sensitivity by acting as a mild calcium antagonist. Med Hypotheses 2005, 64:619-627.

97. Guerrero-Romero F, Tamez-Perez HE, Gonzalez-Gonzalez G, et al.: Oral magnesium supplementation improves insulin sensitivity in nondiabetic subjects with insulin resistance. A double-blind placebocontrolled randomized trial. Diabetes Metab 2004, 30:253-258. 